from what actually occurs. No matter how jobs are obtained or where or what the conditions, most young people settle down very quickly at work and enjoy the security it brings as well as the opportunities to assert themselves as individuals. Although obnoxious initiation practices have disappeared, initiation to employment is almost as meagre as formal training to a job.

Of the kind of jobs taken by teenagers, Carter's analysis shows that the term 'apprenticeship', apart from the nationalized industries and the bigger organizations, in steel, engineering and cutlery, is largely a value-word used primarily to induce recruitment. The average wages of young people are not nearly so high as many adults imagine and is not such a direct cause of delinquency as is suggested. Carter also indicates that the structure of jobs remains as rigid as ever, and the girl in the office still considers herself superior to the shop assistant who, in turn, looks down on the often much better paid factory worker whose working conditions are frequently so much more congenial.

All this, and much more, is contained in this well-documented work, and it is unfortunate that Carter has not highlighted what he considers to be the more important observations arising from his survey. Three of these spring readily to mind. The first is the still prevalent belief that, for the young worker, there is a special kind of job for which he has a particular bent and our vocational guidance services should be developed to find it for him. Few personnel officers would support this basic belief and would like it investigated. Secondly, that the time has come for an appraisal of the Youth Employment Service and, if it is to continue, to provide it with men and services which will enable it to work effectively. Thirdly, is the lamentable fact that industry and commerce is still almost a closed shop to most people outwith. Young people will never be able to obtain real help until the public at large become aware of what goos on behind office and factory doors.

T. H. Hawkins

\section{ECONOMIC PLANNING}

\section{Readings in Mathematical Programming}

By Dr. S. Vajda. Pp. viii +130 . (London : Sir Isaac Pitman and Sons, Ltd., 1962, second edition). $21 s$.

N producing a second edition of his well-known Readings 1 in Linear Programming Dr. Vajda has found it necessary not only to add seven new chapters but also to change the name of the book. The reasons for these changes reflect the growing scope and importance of the subject in the modern world.

Mathematical programming is concerned with such problems as: how best to dispose warehouses between, say, manufacturers and customers so that the distribution costs may be a minimum. Or again : how best to use capital, manpower, machinery and premises as to maximize the profit to shareholders. The importance of being able to solve such problems is self-evident, but is it only in the past five years or so that applications, on a practical scale, have been made possible by the advent of large, general-purpose, electronic digital computers.

In principle the methods of solution should enable nation-wide economic planning and prediction to be made into a precise science although, in fact, no existing computer even approaches the capacity required for such applications.

Vajda's book is an eminently practical one. It does not discuss the fundamental mathematical bases of the methods described, but rather seeks to present practical recipes for solving problems. In general, each chapter starts with the statement of a practical problem, with actual numbers, and then goes on to present, in detail, the method of numerical solution. The book is thus a very suitable one for managers, and others, of limited mathe- matical attainments, and it will be an unfortunate reader who does not find help with his particular planning problem in almost explicit terms.

The new material in this edition covers quadratic programming and discrete (or discontinuous) programming. Both these applications are 'non-linear', and are responsible for the change in title; they are important in modern technology and it is useful to have the lucid exposition which the book provides. The style is terse but readable, and the only real criticism is that the bibliography has expanded by only five references whereas the actual literature published since the first edition is more than ten times as extensive.

A. D. Воотн

\section{THEORY OF NUMERICAL PRACTICE}

\section{Discrete Variable Methods in Ordinary Differential Equations}

By Prof. Peter Henrici. Pp. xi+407. (New York and London: John Wiley and Sons, Inc., 1962.) $87 s$. UMERICAL analysis, beginning as a break-away
province from a domain of general but often nonconstructive theory, has now established a theory of its own. We have Householder's book on finite systems of equations, and Collatz, now available in an English translation, on differential equations. But there is room for a new book on this latter topic, taking account of the extended use and the necessary programming of electronic computation. This development, by the ease with which it can handle vast numerical arrays if these are wellorganized, and by its efficiency with iterative methods, demands a re-assessment of known processes; thus, for example, the Runge-Kutta methods, after falling slightly out of favour, have become prominent again through the work of Gill and others in adapting them to modern computing machinery.

Henrici's book, while owing much to Collatz, has a very up-to-date flavour: particular attention is directed to error estimation, to programming problems, and to the non-linear equation. For the latter, while purely theoretical investigations are still faced with serious obstacles, numerical analysis has a great opportunity to show its powers.

The discrete method for a differential equation $\mathrm{f}\left(x, y, y^{\prime}, y^{\prime \prime}, ..\right)=0$ estimates values $y_{n}$ at points $x_{n}$ in an interval $(a, b)$, when adequate initial or boundary conditions are specified. In the present book, Part 1 deals with one-step methods, by which $y_{n+1}$ is derived from a knowledge of $y_{n}$. Part 2 with multi-step methods where $y_{n+1}$ is made to depend on $k$ predecessors, $y_{n}, y_{n-1}, \ldots$, $y_{n-k+1}$; in these two parts, initial conditions are used. Part 3 is concerned, rather briefly, with boundary value problems. Each of the seven chapters has the same main structure: methods; bounds for the truncation error arising from the replacement of a differential equation by an equation in finite differences; estimates, often with a probability basis, for the rounding-off error; problems, mainly theoretical, sometimes quite searching and often indicating extensions of the main text. The author has explored the recent literature with great thoroughness, and much material has been collected and organized from research memoirs and periodicals.

The reader needs only a normal knowledge of calculus, with a very little about linear algebra, matrix theory and complex variable, so that the book can be regarded as a first course in numerical analysis. But it would be a somewhat severe introduction for the novice; he would be well advised to start on one of the elementary texts, and familiarize himself by desk computation with some of the simpler methods, not worrying too much about finer points of error estimation, until he appreciates the need for the more rigorous and searching account which Henrici provides.
T. A. A. Broadbent 